\title{
Corrigendum to "Assessment of 105 Patients with Angiotensin Converting Enzyme-Inhibitor Induced Angioedema"
}

\author{
Eva Rye Rasmussen (D), ${ }^{1}$ Christian von Buchwald, ${ }^{1}$ Mia Wadelius $\left(\mathbb{D},{ }^{2}\right.$ \\ Sumangali Chandra Prasad, ${ }^{3}$ Shailajah Kamaleswaran, ${ }^{3}$ Kawa Khaled Ajgeiy, ${ }^{3}$ \\ Georg Authried, ${ }^{3}$ Kristine Appel U. Pallesen, ${ }^{3}$ and Anette Bygum (iD) ${ }^{3}$ \\ ${ }^{1}$ Department of Otorhinolaryngology, Head \& Neck Surgery and Audiology, Rigshospitalet, University of Copenhagen, \\ København, Denmark \\ ${ }^{2}$ Department of Medical Sciences, Clinical Pharmacology and Science for Life Laboratory, Uppsala University, Uppsala, Sweden \\ ${ }^{3}$ Department of Dermatology and Allergy Centre, Odense University Hospital, Odense, Denmark
}

Correspondence should be addressed to Eva Rye Rasmussen; eva.rye.rasmussen@dadlnet.dk

Received 15 February 2018; Accepted 18 February 2018; Published 1 March 2018

Copyright (c) 2018 Eva Rye Rasmussen et al. This is an open access article distributed under the Creative Commons Attribution License, which permits unrestricted use, distribution, and reproduction in any medium, provided the original work is properly cited.

In the article titled "Assessment of 105 Patients with Angiotensin Converting Enzyme-Inhibitor Induced Angioedema” [1], there was an error in the Results section where the text reading "In multivariate logistic regression analysis, angioedema located in the head and neck region was nonsignificantly associated with admission (odds ratio (OR) 5.9 ( $p=0.15,95 \%$ CI 0.53-98.49)), while angioedema in peripheral sites was significantly associated with not being admitted (OR $0.15(p=$ 0.05 95\% CI, 0.01-0.95) (Table 6))" should be corrected as follows.

"In multivariate logistic regression analysis, angioedema located in the head and neck region was nonsignificantly associated with admission (odds ratio (OR) 6.93 ( $p=0.14$, 95\% CI 0.53-98.49)), while angioedema in peripheral sites was significantly associated with not being admitted (OR 0.15 $(p=0.05$ 95\% CI, 0.01-0.95) (Table 6)).”

\section{References}

[1] E. Rye Rasmussen, C. von Buchwald et al., "Assessment of 105 patients with angiotensin converting enzyme-inhibitor induced angioedema," International Journal of Otolaryngology, vol. 2017, Article ID 1476402, 7 pages, 2017. 


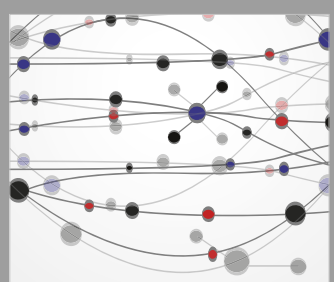

The Scientific World Journal
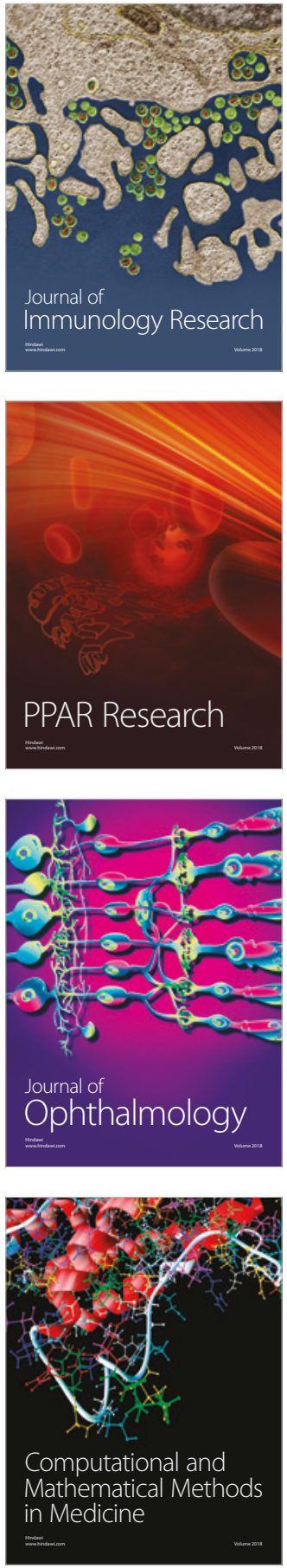

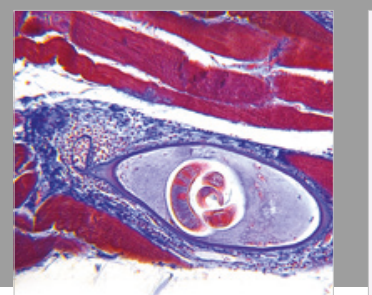

Gastroenterology Research and Practice

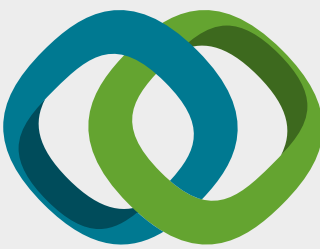

\section{Hindawi}

Submit your manuscripts at

www.hindawi.com
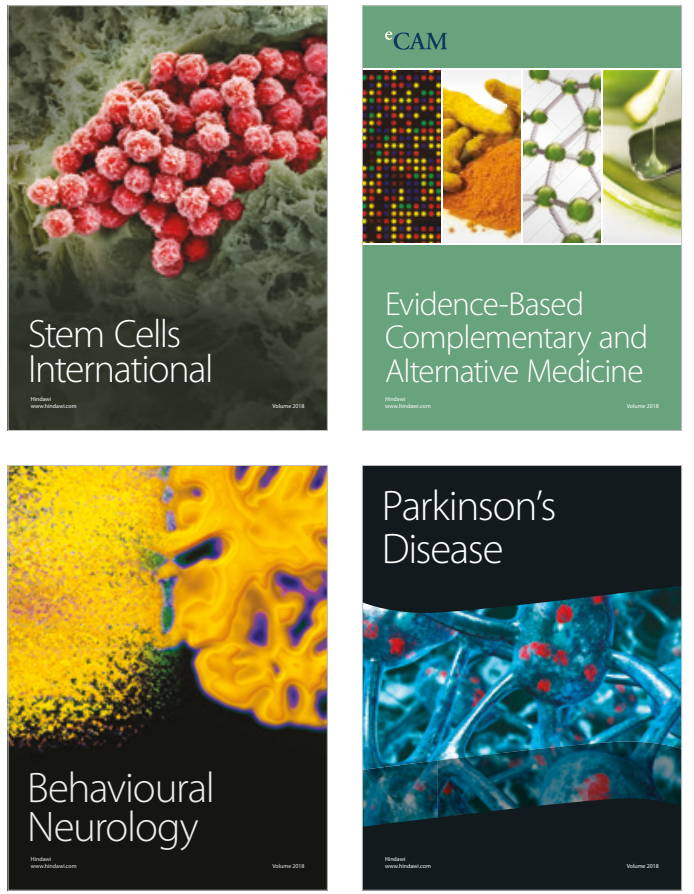

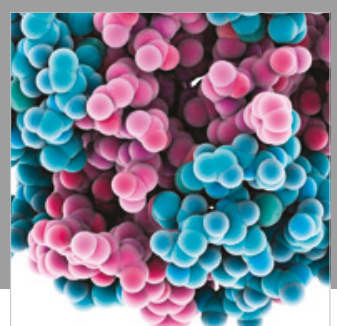

ournal of

Diabetes Research

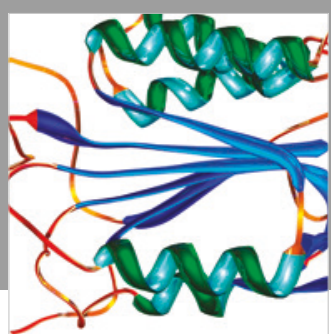

Disease Markers
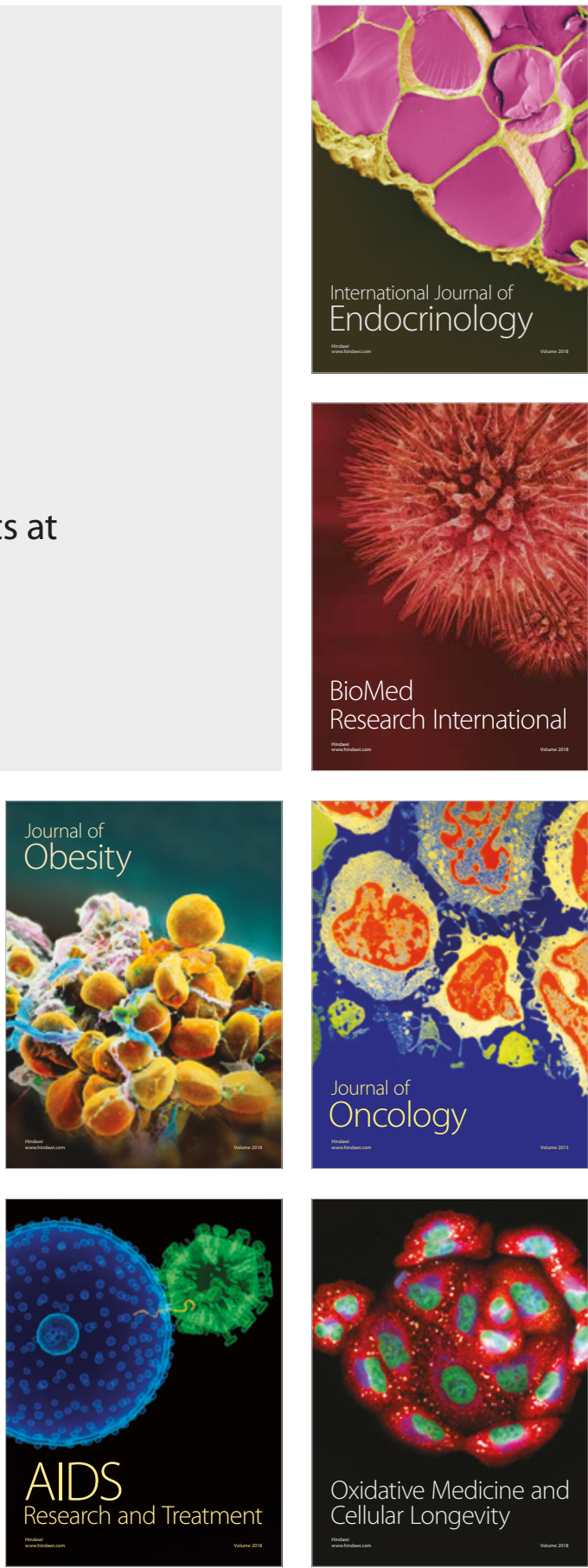